\title{
Penerapan Algoritma FP-Growth Untuk Menentukan Pola Pembelian Konsumen Pada AHASS Cibadak
}

\author{
Satia Suhada1, Daniel Ratag ${ }^{2}$, Gunawan $^{3}$, Dede Wintana ${ }^{4}$, Taufik Hidayatulloh ${ }^{5}$ \\ ${ }^{1}$ Sekolah Tinggi Manajemen Informatika dan Komputer Nusa Mandiri \\ e-mail: satia.sha@nusamandiri.ac.id \\ 2,3,4Universitas Bina Sarana Informatika \\ e-mail: ${ }^{2}$ danielratag539@gmail.com, ${ }^{3}$ gunawan.gnz@bsi.ac.id, ${ }^{4}$ dede.dwe@bsi.ac.id, \\ 5taufik.tho@bsi.ac.id
}

\begin{abstract}
Abstraksi
Dalam sebuah perusahaan, memperoleh laba keuntungan dan keberlanjutan kehidupan perusahaan merupakan sebuah tujuan utama. Dalam mencapai tujuannya, penjualan menjadi salah satu fungsi pemasaran yang paling penting. Semakin lama data pada transaksi penjualan akan meningkat dan termasuk seiring meningkatnya permintaan konsumen yang harus diimbangi dengan teknologi sistem informasi untuk proses penjualan dan pelaporan hasil penjualannya. Penelitian ini bertujuan untuk menentukan pola pembelian konsumen dengan salah satu algoritma asosiasi yaitu FP-Growth dengan data transaksi penjualan di PT. Selamat Lestari Mandiri Cibadak. Data transaksi penjualan memiliki 13 atribut dan 216 catatan. Berdasarkan penelitian yang diperoleh dari hasil penjualan suku cadang, terdapat beberapa item produk yang paling banyak dijual secara simultan serta bersamaan di PT. Selamat Lestari mandiri Cibadak. Dengan algoritma FP-Growth untuk menganalisa pola pembelian konsumen sangat bermanfaat bagi perusahaan, karena PT. Selamat Lestari Mandiri Cibadak akan mengetahui suku cadang mana yang banyak dibeli secara simultan serta bersamaan dan membantu dalam pemesanan suku cadang pada kantor pusat.
\end{abstract}

\begin{abstract}
In a company, gaining profit and sustainability of the company's life is a major goal. In achieving its objectives, sales become one of the most important marketing functions. The longer the data on the sales transaction will increase and include the increasing demand of consumers who have to be balanced with information system technology for the sales process and the reporting of the proceeds. This research aims to determine the pattern of consumer purchase with one of the associated algorithm of FP-Growth with sales transaction data in PT. Selamat Lestari Mandiri Cibadak. The sales transaction Data has 13 attributes and 216 records. Based on research obtained from the results of the sale of parts, there are some products that are sold simultaneously in PT. Selamat Lestari Mandiri Cibadak. With the FP-Growth algorithm to analyze the consumer buying patterns are very beneficial for the company, because PT. Selamat Lestari Mandiri Cibadak will know which parts are purchased simultaneously and assist in ordering Sparepart at head office.
\end{abstract}

Keywords: Association, FP-Growth, Sales, Sparepart

\section{Pendahuluan}

Saat ini perkembangan teknologi informasi memberikan dampak pertumbuhan jumlah data yang cepat dan terus menerus dikumpulkan dalam sebuah basis data (Elwani, 2017). Begitu pula dengan data transaksi penjualan semakin lama akan bertambah dan semakin banyak termasuk permintaan konsumen yang terus meningkat maka harus diimbangi dengan teknologi untuk proses penjualan dan pelaporan hasil penjualannya (Junaidi,
2019). Pelaporan hasil penjualan dan data transaksi penjualan biasanya hanya digunakan sebagai arsip dan tidak diketahui manfaat ke depannya, padahal hasil penjualan tersebut dapat digunakan salah satunya untuk memprediksi permintaan barang dari konsumen (Mahmudah \& Aribowo, 2014).

Agar data transaksi penjualan dapat menjadi sebuah informasi yang bermanfaat untuk mendukung pengambilan keputusan bisnis maka dibutuhkan suatu teknologi 
yaitu data mining (Gunadi \& Sensuse, 2012). Penelitian ini menggunakan algoritma FP-Growth yang merupakan salah satu algoritma asosiasi dalam data mining. Algoritma FP-Growth merupakan pengembangan dari metode Apriori sebagai salah satu alternatif untuk menentukan himpunan data yang paling sering muncul (Frequent itemset) dalam sebuah kumpulan data kemudian membangkitkan struktur data Tree atau disebut dengan Frequent Pattern Tree (FP-Tree) (Fajrin \& Maulana, 2018).

Algoritma FP-Growth juga dapat diimplementasikan untuk menemukan pola peminjaman buku pada sebuah perpustakaan, karena dengan algoritma ini dapat menunjukan perbandingan pola yang terbentuk dengan memasukan nilai support dan confidence yang berbeda pada data transaksi yang sama (Kadafi, 2018).

Algoritma tersebut melakukan analisis terhadap suatu transaksi penjualan pada PT. Selamat Lestari Mandiri Cibadak yang mana bertujuan untuk merancang strategi penjualan atau pemasaran yang efektif, selain itu analisis ini juga dapat menemukan pola pembelian produk-produk yang sering dibeli secara bersamaan atau produk yang memiliki kecenderungan muncul bersamaan dalam sebuah transaksi dari data transaksi penjualan yang pada umumnya berukuran besar (Firman, 2017).

Dalam sebuah perusahaan, memperoleh laba keuntungan dan keberlangsungan hidup perusahaan merupakan sebuah tujuan utama. Dalam mencapai tujuan, penjualan menjadi salah satu fungsi pemasaran yang berperan penting. Dampak positif dari banyaknya laba yang diperoleh, kegiatan dalam perusahaan dapat berkembang dengan baik, jumlah aktiva dan modal mengalami peningkatan serta bidang usaha dapat dikembangkan dan diperluas secara berkesinambungan (Sukrawan, Arifin, \& Nurcahyawati, 2016).

Association rules adalah suatu proses pada data mining untuk menentukan semua aturan asosiatif yang memenuhi syarat minimum untuk support dan confidence pada sebuah database. Kedua syarat tersebut akan digunakan untuk interesting association rules dan dibandingkan dengan batasan yang telah ditentukan yaitu support dan confidence (Rusdiaman \& Setiyono, 2018).

Pada teknik data mining, asosiasi dikenal juga sebagai salah satu dasar dari teknik data mining lainnya. Secara khusus, salah satu tahap analisis asosiasi yang menarik perhatian banyak peneliti untuk menghasilkan algoritma yang efisien, yaitu analisis pola frekuensi tinggi (frequent pattern mining) (Fauzy, Saleh W, \& Asror, 2016).

Aturan asosiasi dalam data mining mempunyai dua langkah proses yaitu mencari item-set yang sering muncul untuk menentukan minimum support, dan menghasilkan aturan asosiasi yang kuat dari item-set tersebut sehingga memenuhi untuk minimum support dan minimum confidence.

Minimum support adalah parameter yang digunakan dalam menentukan pola dalam data mining untuk menentukan statistik dari pola-pola yang signifikan. Sedangkan confidence adalah suatu ukuran yang menunjukkan hubungan antar dua item secara conditional (berdasarkan suatu kondisi tertentu) (Junaidi, 2019).

Algoritma FP-Growth merupakan pengembangan dari algoritma apriori, sehingga kekurangan dari algoritma apriori diperbaiki oleh algoritma fp-growth. Pada algoritma apriori diperlukan generate candidate untuk mendapatkan frequent item sets, tetapi untuk algoritma fp-growth generate candidate tidak dilakukan karena telah menggunakan konsep pembangunan tree dalam pencarian frequent item sets yang disebut dengan FP-Tree. Dengan menggunakan fp-tree, maka dapat langsung mengekstrak frequent item sets dari fp-tree (Idayani, Sutardi, \& Muchlos, 2017).

FP-growth adalah salah satu cara alternatif untuk menemukan himpunan data yang paling sering muncul tanpa menggunakan generasi kandidat. Fpgrowth membangun kontruksi data fp-tree yang sangat dikompresi, dan mengurangi data asli. Algoritma fp-growth melakukan scan database yang sama sebanyak dua kali. Scanning database yang pertama, kita dapat memperoleh frequent 1-item-set, dan scanning database yang kedua, kita dapat memfilter database non-frequent item, selebihnya fp-tree dihasilkan secara bersamaan (Ghozali, Ehwan, \& Sugiharto, 2017).

\section{Metode Penelitian}

\subsection{Tahapan Penelitian}

Dalam penelitian ini terdapat enam tahapan yang dilakukan berdasarkan model 
Cross Industry Standard Process for Data Mining (CRISP-DM) (Larose \& Larose, 2015) yang terdiri dari:

1. Tahap Pemahaman Bisnis (Business Understanding)

Pada tahap ini ditentukan untuk penentuan tujuan dari penelitian yaitu menemukan pola berupa produkproduk yang sering dibeli bersamaan atau produk yang cenderung muncul bersama dalam sebuah transaksi dari data transaksi penjualan PT. Selamat Lestari Mandiri Cibadak.

2. Tahap Pemahaman Data (Data Understanding)

Data yang digunakan adalah data primer yang didapat dari hasil riset pada PT. Selamat Lestari Mandiri Cibadak. Data ini bersumber dari salah satu admin yang bekerja pada perusahaan tersebut. Data tersebut terdiri dari 13 atribut.

3. Tahap Persiapan Data (Data Preparation) Pada tahap ini dilakukan pengolahan data transaksi penjualan, jumlah data yang diperoleh pada penelitian ini sebanyak 216 record (Suryono, 2019). Data tersebut masih terdapat data anomali, oleh karena itu sebelum melakukan pemodelan perlu dilakukan Data Preparation meliputi; Rename by Replacing, mencoba melakukan pengisian missing value, mengubah data numeric menjadi binomial.

4. Tahap Pemodelan (Modelling)

Tahap ini dilakukan setelah melakukan data preparation, yaitu melakukan pemodelan dengan menggunakan metode asosiasi algoritma FP-Growth.

5. Tahap Evaluasi (Evaluation)

Tahap ini dilakukan pengujian terhadap model yang dihasilkan untuk mendapatkan informasi model yang akurat.

6. Tahap Deployment

Dari model yang telah dihasilkan maka perlu diuji dengan menggunakan data baru dan dilakukan kembali evaluasi untuk keakuratan data.

Menjelaskan kronologis penelitian, termasuk desain penelitian, prosedur penelitian (dalam bentuk algoritma, Pseudocode atau lainnya), bagaimana untuk menguji dan akuisisi data. Deskripsi dari program penelitian harus didukung referensi, sehingga penjelasan tersebut dapat diterima secara ilmiah.
Tabel dan Gambar disajikan dalam perataan rata tengah, seperti yang ditunjukkan pada Tabel 1 dan Gambar 1 , serta harus dikutip dalam naskah.

\subsection{Populasi dan Sampel Penelitian}

Dalam penelitian ini, populasi merupakan data primer yang didapat dari sebuah perusahaan yaitu PT. Selamat Lestari Mandiri Cibadak, sedangkan teknik sampling yang digunakan untuk data testing adalah metode simple random sampling. Metode paling sederhana dan paling umum untuk memilih sampel, di mana sampel dipilih unit demi unit, dengan probabilitas pemilihan yang sama untuk setiap unit pada setiap undian (Singh, 2010).

\subsection{Metode Analisis Data}

Gambar 1 merupakan langkahlangkah dalam metode analisis data:

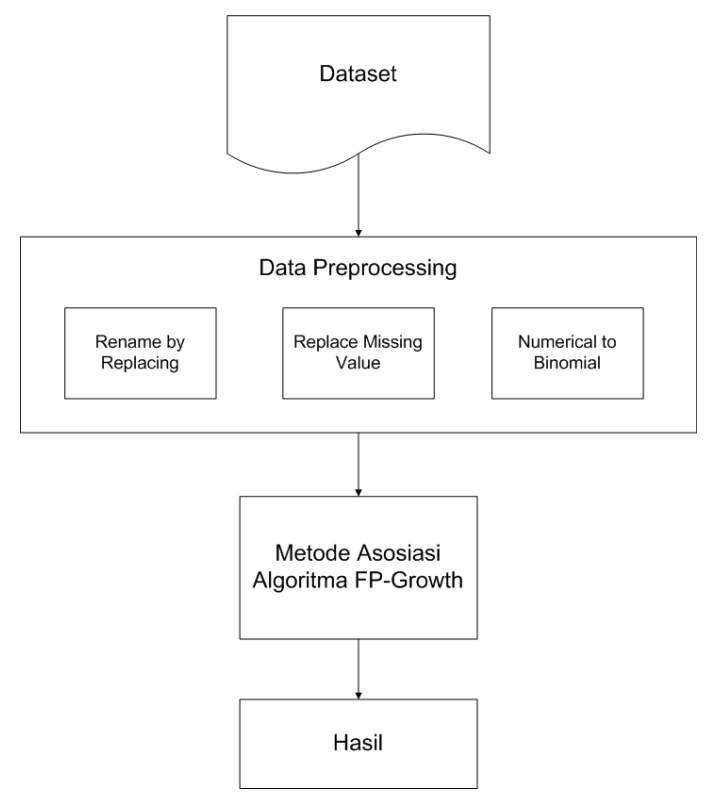

Gambar 1. Metode Analisis Data

1. Dataset

Langkah pertama yang dilakukan adalah menyiapkan dataset yang akan diteliti, lalu data tersebut disesuaikan dengan kebutuhan penelitian seperti dalam penelitian ini yaitu untuk menemukan pola pembelian pelanggan dengan menggunakan data transaksi penjualan.

\section{Data Preprocessing}

Tahap pertama Data Preprocessing adalah Rename by Replacing. Proses ini adalah menghapus bagian yang tidak 
diinginkan dari nama atribut seperti space, tanda kurung, atau karakter yang tidak diinginkan. Tahap kedua Replace Missing Value. Proses ini adalah memasukkan nilai mean dari masing-masing variabel apabila record kosong. Tahap ketiga Numerical to Binomial. Proses ini adalah merubah nilai yang bersifat numerik menjadi binomial agar dapat diproses oleh algoritma FPGrowth.

3. Metode Asosiasi Algoritma FP-Growth Langkah selanjutnya yaitu melakukan pengujian menggunakan metode asosiasi algoritma FP-Growth.

\section{Hasil}

Hasil pengujian tersebut menghasilkan pola pembelian pelanggan terhadap barang yang terdapat pada PT. Selamat Lestari Mandiri Cibadak.

\section{Hasil dan Pembahasan}

\subsection{Pengumpulan Data}

Teknik pengumpulan data dilakukan dengan cara riset langsung pada sebuah perusahaan yang berada di Sukabumi yaitu PT. Selamat Lestari Mandiri Cibadak. Dataset diambil dari 10 produk terjual yang paling tertinggi seperti pada tabel 1:

Tabel 1. Produk Terjual Paling Tertinggi
Data sampel transaksi penjualan terlihat pada tabel 2 berikut ini:

Tabel 2. Data Sampel Transaksi Penjualan

\begin{tabular}{|c|c|}
\hline \multirow{4}{*}{$\begin{array}{c}\text { No Transaksi } \\
\text { SLM.NSC.19.0063054 }\end{array}$} & Produk \\
\hline & $\begin{array}{llll}\text { OLI } & \text { MPX2 } & 10 \mathrm{~W} 30 & \mathrm{SL} \\
0.8 \mathrm{LIDE} & \end{array}$ \\
\hline & $\begin{array}{l}\text { SCOOTER GEAR OIL } \\
\text { (120ML) IDE }\end{array}$ \\
\hline & PIECE SLIDE \\
\hline \multirow[t]{2}{*}{ SLM.NSC. 19.0063590} & $\begin{array}{l}\text { SCOOTER GEAR OIL } \\
\text { (120ML) IDE }\end{array}$ \\
\hline & $\begin{array}{l}\text { SPARK PLUG CPR9EA- } \\
9 \text { (NG) }\end{array}$ \\
\hline \multirow[t]{4}{*}{ SLM.NSC.19.0063031 } & $\begin{array}{llll}\text { OLI } & \text { MPX1 } & 10 W 30 & \text { SL } \\
0,8 L & \text { IDE }\end{array}$ \\
\hline & BRAKE SHOE \\
\hline & OIL SEAL 20.8X52X7.5 \\
\hline & $\begin{array}{l}\text { HONDA M/C GENUINE } \\
\text { COOLANT }\end{array}$ \\
\hline \multirow[t]{3}{*}{ SLM.NSC.19.0071591 } & BRAKE SHOE \\
\hline & $\begin{array}{llll}\text { OLI } & \text { MPX2 } & 10 W 30 & \text { SL } \\
0,8 L & \text { IDE } & & \end{array}$ \\
\hline & $\begin{array}{l}\text { HONDA M/C GENUINE } \\
\text { COOLANT }\end{array}$ \\
\hline \multirow[t]{3}{*}{ SLM.NSC.19.0063037 } & $\begin{array}{l}\text { OLI MPX1 10W30 SL 1L } \\
\text { IDE }\end{array}$ \\
\hline & $\begin{array}{l}\text { SPARK PLUG CPR9EA- } \\
9 \text { (NG) }\end{array}$ \\
\hline & OIL SEAL $20.8 \times 52 X 7.5$ \\
\hline SLM.NSC.19.0062436 & $\begin{array}{l}\text { SPARK PLUG CPR9EA- } \\
9 \text { (NG) }\end{array}$ \\
\hline QTY & $\begin{array}{llll}\text { OLI } & \text { MPX2 } & 10 W 30 & \text { SL } \\
0,8 L & \text { IDE }\end{array}$ \\
\hline \multirow[t]{2}{*}{8595} & BRAKE SHOE \\
\hline & RACE STEERING KIT \\
\hline \multirow{2}{*}{ 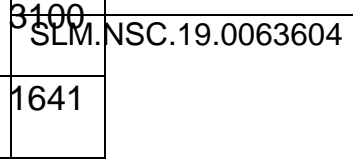 } & $\begin{array}{l}\text { HONDA M/C GENUINE } \\
\text { COOLANT }\end{array}$ \\
\hline & $\begin{array}{llll}\text { OLI } & \text { MPX2 } & 10 W 30 & \mathrm{SL} \\
0.8 L I D E & \end{array}$ \\
\hline 764M.NSC. 19.0063502 & RACE STEERING KIT \\
\hline \multirow[t]{2}{*}{749} & $\begin{array}{llll}\text { OLI } & \text { MPX1 } & 10 W 30 & \text { SL } \\
0,8 L & \text { IDE }\end{array}$ \\
\hline & $\begin{array}{l}\text { SCOOTER GEAR OIL } \\
\text { (120ML) IDE }\end{array}$ \\
\hline \multirow{2}{*}{68 का.M.NSC. 19.0067431} & PIECE SLIDE \\
\hline & $\begin{array}{l}\text { HONDA M/C GENUINE } \\
\text { COOLANT }\end{array}$ \\
\hline \multirow[t]{2}{*}{573} & BRAKE SHOE \\
\hline & $\begin{array}{llll}\text { OLI } & \text { MPX2 } & 10 W 30 & \text { SL } \\
0,8 L & \text { IDE }\end{array}$ \\
\hline \multirow{2}{*}{ 542M.NSC. 19.0071940} & OIL SEAL 20.8X52X7.5 \\
\hline & $\begin{array}{llll}\text { OLI } & \text { MPX2 } & 10 W 30 & \text { SL } \\
0,8 L & \text { IDE }\end{array}$ \\
\hline SLM.NSC.19.0071952 & $\begin{array}{l}\text { HONDA M/C GENUINE } \\
\text { COOLANT }\end{array}$ \\
\hline
\end{tabular}




\begin{tabular}{|l|l|}
\hline \multirow{3}{*}{ SLM.NSC.19.0071955 } & OIL SEAL 20.8X52X7.5 \\
\cline { 2 - 2 } & PIECE SLIDE \\
\cline { 2 - 2 } & RACE STEERING KIT \\
\cline { 2 - 2 } SLM.NSC.19.0071963 & $\begin{array}{l}\text { OLI MPX2 10W30 SL 0,8L } \\
\text { IDE }\end{array}$ \\
\cline { 2 - 2 } & BRAKE SHOE \\
\cline { 2 - 2 } & RACE STEERING KIT \\
\hline SLM.NSC.19.0071964 & $\begin{array}{l}\text { OLI MPX1 10W30 SL 1L } \\
\text { IDE }\end{array}$ \\
\cline { 2 - 2 } & OIL SEAL 20.8X52X7.5 \\
\hline SLM.NSC.19.0071973 & $\begin{array}{l}\text { OLI MPX1 10W30 SL 0,8L } \\
\text { IDE }\end{array}$ \\
\cline { 2 - 2 } & $\begin{array}{l}\text { HONDA M/C GENUINE } \\
\text { COOLANT }\end{array}$ \\
\hline SLM.NSC.19.0071982 & $\begin{array}{l}\text { SPARK PLUG CPR9EA-9 } \\
\text { (NG) }\end{array}$ \\
\cline { 2 - 2 } & RACE STEERING KIT \\
\hline SLM.NSC.19.0071990 & OLI MPX2 10W30 SL 0,8L \\
\hline
\end{tabular}

\begin{tabular}{|l|l|}
\hline \multirow{5}{*}{ SLM.NSC.19.0072211 } & IDE \\
\cline { 2 - 2 } & $\begin{array}{l}\text { HONDA M/C GENUINE } \\
\text { COOLANT }\end{array}$ \\
\cline { 2 - 2 } & $\begin{array}{l}\text { OLI MPX STEERING KIT 10W30 SL 1L } \\
\text { IDE }\end{array}$ \\
\cline { 2 - 2 } & $\begin{array}{l}\text { HONDA M/C GENUINE } \\
\text { COOLANT }\end{array}$ \\
\cline { 2 - 2 } & PIECE SLIDE \\
\cline { 2 - 2 } SLM.NSC.19.0072213 & $\begin{array}{l}\text { OIL SEAL 20.8X52X7.5 } \\
\text { (120ML) IDE }\end{array}$ \\
\cline { 2 - 2 } & PIECE SLIDE \\
\hline SLM.NSC.19.0072216 & $\begin{array}{l}\text { OLI MPX2 10W30 SL 0,8L } \\
\text { IDE }\end{array}$ \\
\cline { 2 - 2 } & OIL SEAL 20.8X52X7.5 \\
\hline SLM.NSC.19.0072219 & BRAKE SHOE \\
\cline { 2 - 2 } & $\begin{array}{l}\text { SPARK PLUG CPR9EA-9 } \\
\text { (NG) }\end{array}$ \\
\hline
\end{tabular}

Pada gambar 2 merupakan bentuk format itemset yang akan digunakan didalam proses pengolahan data menggunakan RapidMiner.

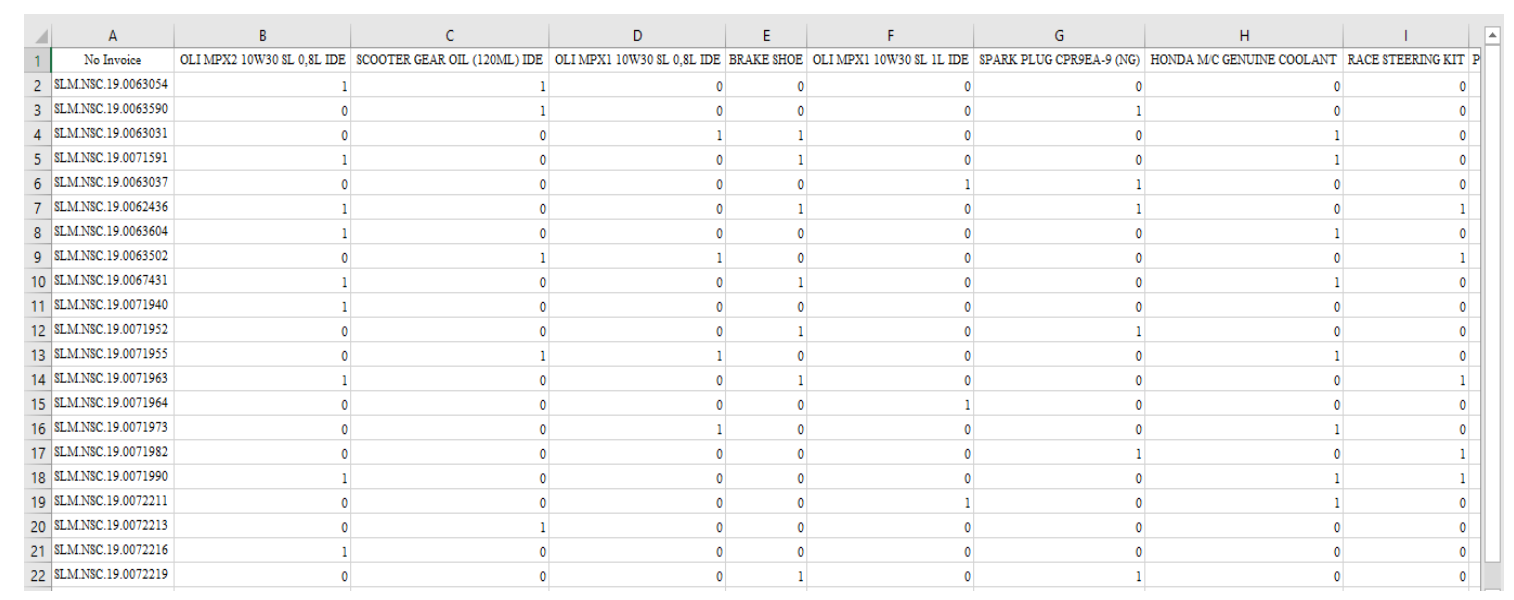

Gambar 2. Dataset Transaksi Penjualan

Keterangan:

1. No Invoice merupakan ID transaksi penjualan barang.

2. OLI MPX2 10W30 SL 0,8L IDE, SCOOTER GEAR OIL (120ML) IDE, OLI MPX1 10W30 SL 0,8L IDE, BRAKE SHOE, dll merupakan barang-barang yang dijual pada perusahaan tersebut.

3. False menandakan bahwa barang tersebut tidak dibeli oleh pembeli.
4. True menandakan bahwa barang tersebut dibeli oleh pembeli.

\subsection{Penerapan Algoritma FP-Growth}

Eksperimen dan pengujian dalam penelitian dilakukan menggunakan algoritma FP-Growth. Eksperimen ini dilakukan terhadap dataset yang telah divalidasi berdasarkan hasil data preprocessing yang telah dilakukan menggunakan tools RapidMiner dengan tahapan sebagai berikut: 


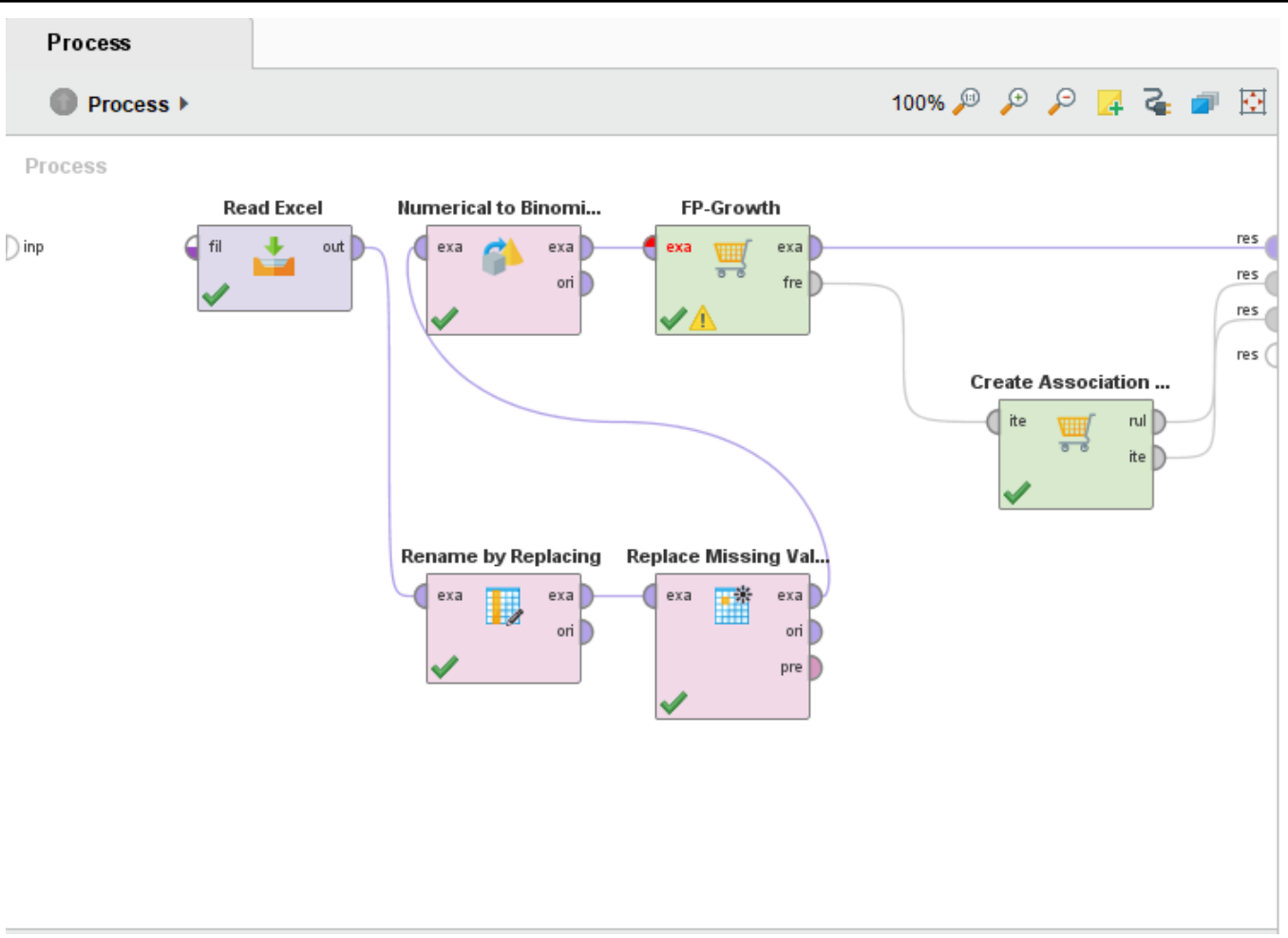

Gambar 3. Tahapan Validasi Data Menggunakan Tools Rapid Miner

Selanjutnya menentukan nilai minimum support dan minimum confidence yang paling tepat untuk memperoleh frequent itemset yang paling baik.

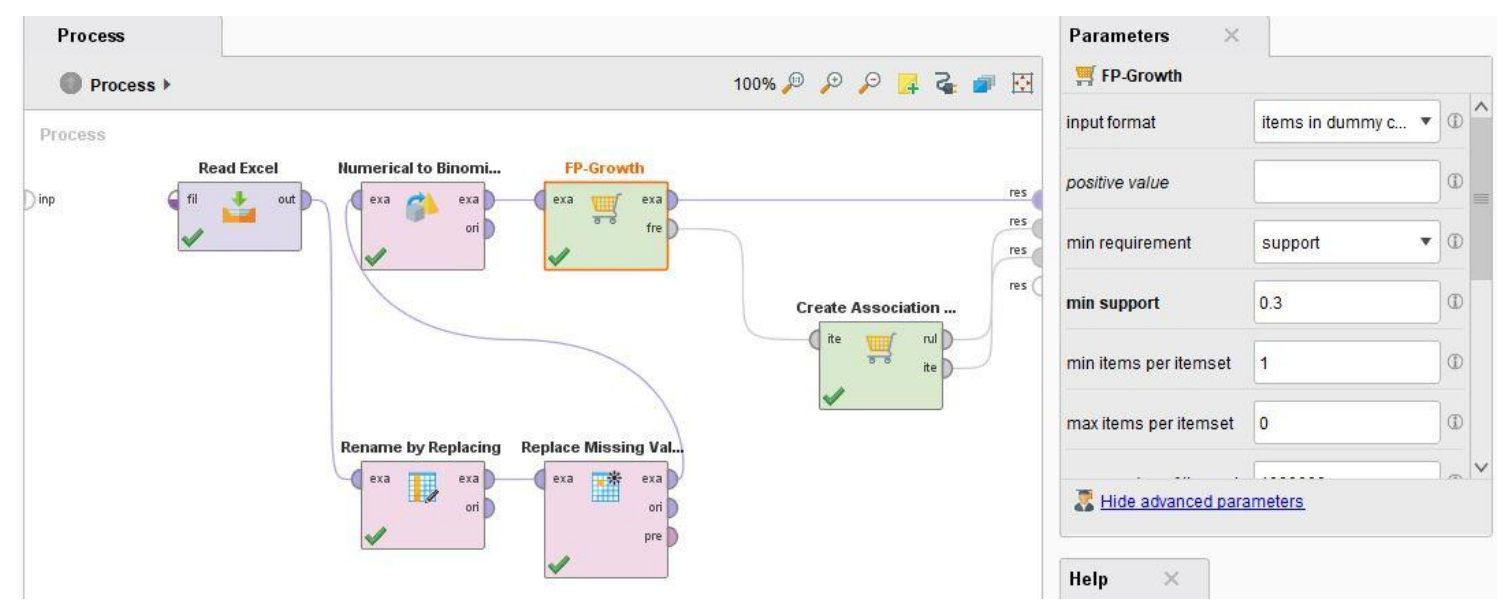

Gambar 4. Menentukan Minimum Support 


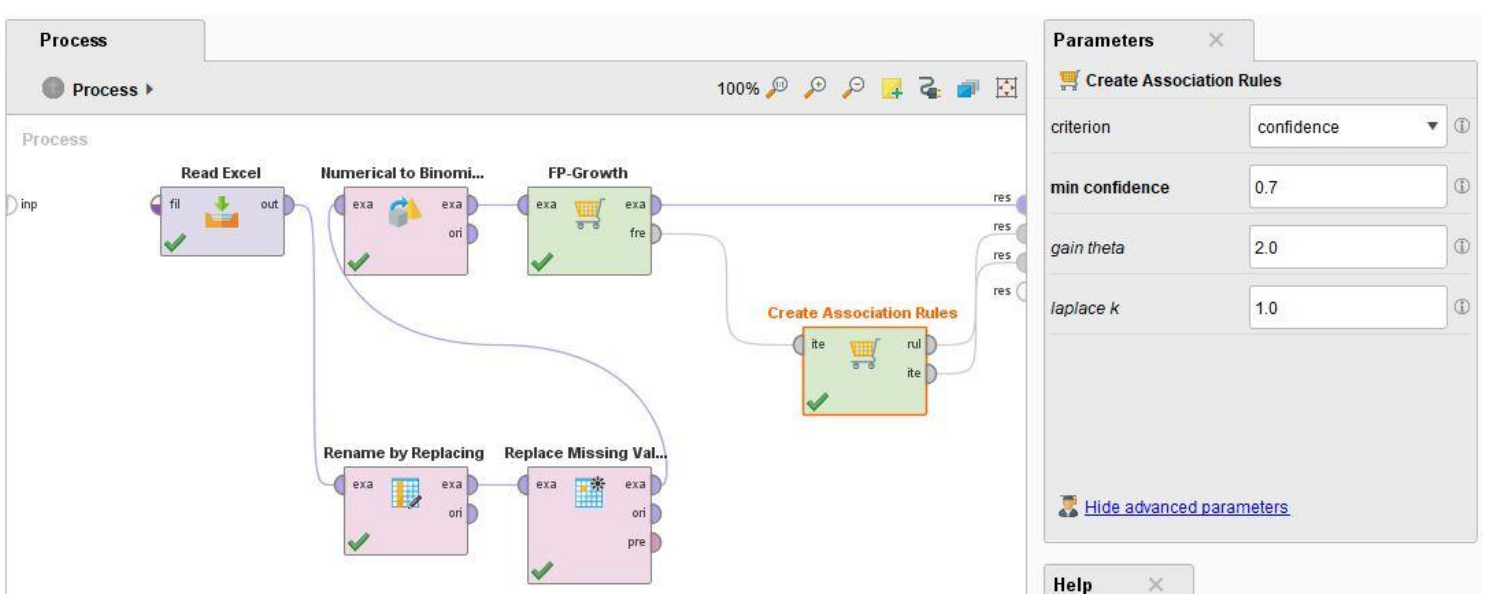

Gambar 5. Menentukan Minimum Confidence

\subsection{Hasil Pemodelan dengan Algoritma FP-Growth}

Pada tabel 3 berikut ini merupakan hasil pemodelan data berdasarkan nilai support paling tinggi menggunakan algoritma FP-Growth.

Tabel 3. Hasil Pemodelan dengan Algoritma FP-Growth

\begin{tabular}{|c|l|l|l|}
\hline \multirow{2}{*}{ Support } & \multicolumn{1}{|c|}{ Item 1 } & \multicolumn{1}{c|}{ Item 2 } & Item 3 \\
\hline 0.429 & OLIMPX210W30SL08LIDE & & \\
\hline 0.381 & HONDAMCGENUINECOOLANT & & \\
\hline 0.333 & BRAKESHOE & & \\
\hline 0.333 & OILSEAL208X52X75 & & \\
\hline 0.286 & SPARKPLUGCPR9EA9NG & & \\
\hline 0.238 & RACESTEERINGKIT & & \\
\hline 0.238 & SCOOTERGEAROIL120MLIDE & & \\
\hline 0.19 & OLIMPX110W30SL08LIDE & & \\
\hline 0.19 & PIECESLIDE & & \\
\hline 0.143 & OLIMPX110W30SL1LIDE & & \\
\hline 0.19 & OLIMPX210W30SL08LIDE & HONDAMCGENUINECOOLANT & \\
\hline 0.19 & OLIMPX210W30SL08LIDE & BRAKESHOE & \\
\hline 0.095 & OLIMPX210W30SL08LIDE & OILSEAL208X52X75 & \\
\hline 0.143 & OLIMPX210W30SL08LIDE & RACESTEERINGKIT & \\
\hline 0.095 & OLIMPX210W30SL08LIDE & PIECESLIDE & \\
\hline 0.143 & HONDAMCGENUINECOOLANT & BRAKESHOE & \\
\hline 0.095 & HONDAMCGENUINECOOLANT & OILSEAL208X52X75 & \\
\hline 0.143 & HONDAMCGENUINECOOLANT & OLIMPX110W30SL08LIDE & \\
\hline 0.095 & HONDAMCGENUINECOOLANT & PIECESLIDE & \\
\hline 0.095 & BRAKESHOE & OILSEAL208X52X75 & \\
\hline 0.143 & BRAKESHOE & SPARKPLUGCPR9EA9NG & \\
\hline 0.095 & BRAKESHOE & RACESTEERINGKIT & \\
\hline 0.095 & OILSEAL208X52X75 & SPARKPLUGCPR9EA9NG & \\
\hline 0.143 & OILSEAL208X52X75 & OLIMPX110W30SL1LIDE & \\
\hline 0.095 & SPARKPLUGCPR9EA9NG & RACESTEERINGKIT & \\
\hline 0.095 & SCOOTERGEAROIL120MLIDE & OLIMPX110W30SL08LIDE & \\
\hline 0.095 & SCOOTERGEAROIL120MLIDE & PIECESLIDE & \\
\hline 0.095 & OLIMPX210W30SL08LIDE & HONDAMCGENUINECOOLANT & BRAKESHOE \\
\hline 0.095 & OLIMPX210W30SL08LIDE & BRAKESHOE & \\
\hline & & & \\
\hline
\end{tabular}




\subsection{Hasil Association Rules}

Hasil dari perhitungan menggunakan RapidMiner menghasilkan tiga rules. Hasil yang didapat dari Association Rules juga menjelaskan bahwa dengan nilai confidence $70 \%$ didapatkan nilai confidence tertinggi yaitu 1.000 pada setiap pembelian produk OLI MPX2 10W30 SL 0,8L IDE dapat dipastikan akan membeli BRAKESHOE dan RACESTEERINGKIT.

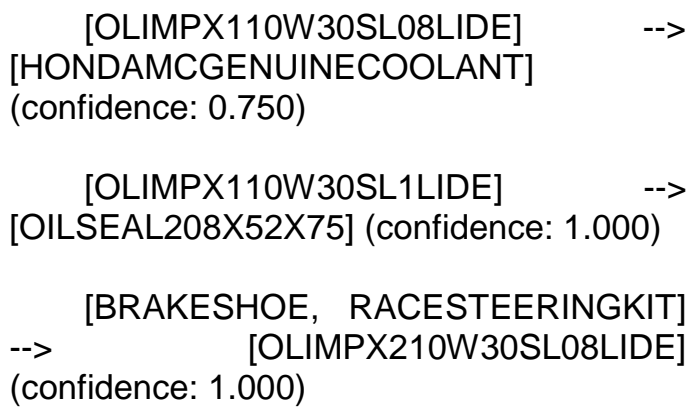

[BRAKESHOE, RACESTEERINGKIT] -> [OLIMPX210W30SL08LIDE] (confidence: 1.000)

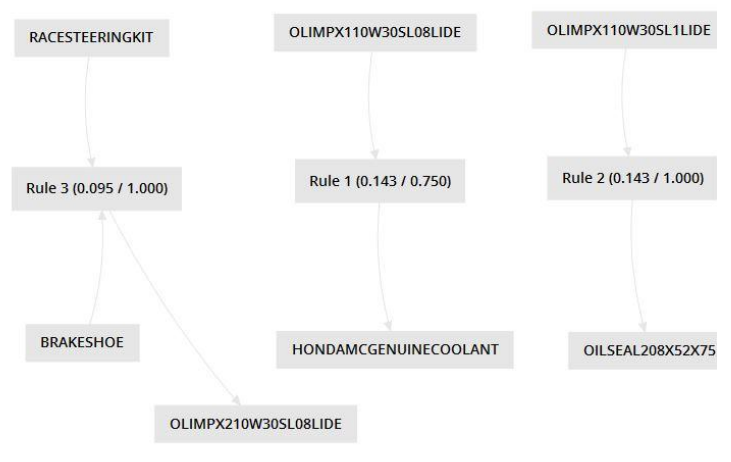

Gambar 6. Graph Rule

\section{Kesimpulan}

Berdasarkan hasil penelitian dan pembahasan dapat ditarik beberapa kesimpulan, yaitu hasil penjualan dari sparepart motor sport yang paling banyak terjual di PT. Selamat Lestari Mandiri Cibadak bisa diketahui dengan menggunakan algoritma FP-Growth. Sparepart yang memenuhi minimum support dan minimun confidence serta yang banyak terjual adalah OLI MPX2 10W30 SL $0,8 \mathrm{~L}$ IDE, BRAKESHOE, dan RACESTEERINGKIT. Selanjutnya penerapan metode Data Mining dengan algoritma FP-Growth untuk analisis pola pembelian konsumen sangat bermanfaat bagi perusahaan tersebut, karena PT. Selamat Lestari Mandiri Cibadak akan mengetahui sparepart mana yang banyak dibeli dan membantu dalam pemesanan sparepart pada kantor pusat.

\section{Referensi}

Elwani. (2017). PENENTUAN ATURAN ASOSIASI PADA TRANSAKSI PEMINJAMAN BUKU MENGGUNAKAN ALGORITMA FP-GROWTH . Jurnal Informatika, Manajemen Dan Komputer, 15-25.

Fajrin, A. A., \& Maulana, A. (2018). PENERAPAN DATA MINING UNTUK ANALISIS POLA PEMBELIAN KONSUMEN DENGAN ALGORITMA FPGROWTH PADA DATA TRANSAKSI PENJUALAN SPARE PART MOTOR . Kumpulan jurnaL IImu Komputer (KLIK) , 27-36.

Fauzy, M., Saleh W, K. R., \& Asror, I. (2016). PENERAPAN METODE ASSOCIATION RULE MENGGUNAKAN ALGORITMA APRIORI PADA SIMULASI PREDIKSI HUJAN WILAYAH KOTA BANDUNG . Jurnal IImiah Teknologi Informasi Terapan, 221227.

Firman, C. E. (2017). PENENTUAN POLA YANG SERING MUNCUL UNTUK PENJUALAN PUPUK MENGGUNAKAN ALGORITMA FP-GROWTH . Jurnal Informatika, Manajemen dan Komputer, 1-8.

Ghozali, M. I., Ehwan, R. Z., \& Sugiharto, W. H. (2017). ANALISA POLA BELANJA MENGGUNAKAN ALGORITMA FP GROWTH, SELF ORGANIZING MAP (SOM) DAN K MEDOIDS . Jurnal Simetris, 317326.

Gunadi, G., \& Sensuse, D. I. (2012). PENERAPAN METODE DATA MINING MARKET BASKET ANALYSIS TERHADAP DATA PENJUALAN PRODUK BUKU DENGAN MENGGUNAKAN ALGORITMA APRIORI DAN FREQUENT PATTERN GROWTH (FP-GROWTH) : STUDI KASUS PERCETAKAN PT. GRAMEDIA . Jurnal TELEMATIKA MKOM, 118132.

Idayani, R., Sutardi, \& Muchlos, N. F. (2017). PERANCANGAN APLIKASI DATA WAREHOUSE MENGGUNAKAN METODE FPGROWTH UNTUK MEMPREDIKSI PENJUALAN ALAT-ALAT 
KESEHATAN (STUDI KASUS : APOTEK KIMIA FARMA KOREM) . Semantik, 81-94.

Junaidi, A. (2019). Implementasi Algoritma Apriori dan FP-Growth Untuk Menentukan Persediaan Barang. Jurnal SISFOKOM, 61-67.

Kadafi, M. (2018). Penerapan Algoritma FP-GROWTH untuk Menemukan Pola Peminjaman Buku Perpustakaan UIN Raden Fatah Palembang . Jurnal IImu Komputer dan Teknologi Informasi, 52-58.

Larose, D. T., \& Larose, C. D. (2015). Data Mining and Predictive Analytics. Canada: Simultaneously.

Mahmudah, R. R., \& Aribowo, E. (2014). PENGGUNAAN ALGORITMA FPGROWTH UNTUK MENEMUKAN ATURAN ASOSIASI PADA DATA TRANSAKSI PENJUALAN OBAT DI APOTEK (Studi Kasus :
APOTEK UAD) . Jurnal Sarjana Teknik Informatika, 130-129.

Rusdiaman, D., \& Setiyono, A. (2018). ALGORITMA FP-GROWTH DALAM PENEMPATAN LOKASI BARANG DI GUDANG PT. XYZ . Jurnal IImu Pengetahuan dan Teknologi Komputer, 63-70.

Singh, S. (2010). Advanced Sampling Theory with Applications. London: Kluwer Academic Publishers.

Sukrawan, P. G., Arifin, M., \& Nurcahyawati, V. (2016). RANCANG BANGUN SISTEM INFORMASI PEMASARAN DAN PENJUALAN RUMAH PADA PT.SAMI KARYA BERBASIS WEB . Jsika, 1-5.

Suryono. (2019, April 02). Laporan Bagian Penjualan dan Sejarah Perusahaan. (Danil, Interviewer) 